\title{
A umbanda e os processos de saúde-doença
}

\author{
The Umbanda and health-disease processes
}

\author{
Luciana Macedo Ferreira Silva ${ }^{1}$, Fabio Scorsolini-Comin ${ }^{2}$
}

\begin{abstract}
Resumo
O envolvimento em atividades de cunho religioso pode constituir uma estratégia de enfrentamento diante das demandas de saúde-doença. No Brasil, a umbanda destaca-se como religião fortemente associada aos processos de cura, sendo procurada por fiéis de diferentes filiações religiosas. O objetivo deste estudo foi compreender como os processos saúde-doença são interpretados nos estudos científicos que possuem como cenário a umbanda. Trata-se de uma revisão integrativa nas bases/bibliotecas Lilacs, SciELO, PePSIC, PsycINFO e Medline (2007 a 2018). Por meio da aplicação dos critérios de inclusão/ exclusão por dois juízes independentes, foram recuperados 22 estudos na íntegra. A partir dos sentidos disponíveis nessas publicações, pode-se afirmar que, na umbanda, os processos de saúde-doença são identificados como forma de remissão e resgate dos resquícios de vidas passadas, como influências de energias externas do universo espiritual, ou ainda como forma de merecimento pessoal. $\mathrm{O}$ tratamento espiritual foi referido neste corpo de literatura como meio complementar à medicina tradicional, fortalecendo uma perspectiva de saúde-doença que integra aspectos biológicos, psicológicos e culturais tanto na compreensão do adoecimento como nos itinerários terapêuticos.
\end{abstract}

Palavras-chave: Religião. Saúde. Umbanda. Doença e cura.

\begin{abstract}
Involvement in religious activities may be a coping strategy in the face of adversities and health-disease demands. In Brazil, Umbanda stands out as a religion strongly associated with healing processes, being sought by believers of different religious affiliations. The aim of this study was to understand how the health-disease processes are interpreted in the scientific studies that have the Umbanda scenario. From the systematic searches in the Lilacs, SciELO, PePSIC, PsycINFO and Medline databases (2007 to 2018), 22 studies were retrieved. In the Umbanda, from the recovered literature, health-disease processes are identified as a form of remission and rescue of the remnants of past lives, as influences and interferences of external energies of the spiritual universe, or as a form of personal merit. Spiritual treatment is referred to in this body of literature as a complementary means to traditional medicine, strengthening a health-disease perspective that integrates biological, psychological and cultural aspects both in the understanding of illness and in the therapeutic itineraries.
\end{abstract}

Keywords: Religion. Health. Umbanda. Disease and cure.

\footnotetext{
${ }^{1}$ Mestrado em Psicologia pela Universidade Federal do Triângulo Mineiro (UFTM), Uberaba, Minas Gerais, Brasil.

${ }^{2}$ Doutorado em Psicologia pela Universidade de São Paulo (USP), Ribeirão Preto, São Paulo, Brasil. Professor da Escola de Enfermagem de Ribeirão Preto da Universidade de São Paulo (EERP-USP), Ribeirão Preto, São Paulo, Brasil. E-mail: fabio.scorsolini@usp.br
} 


\section{Introdução}

Saúde e doença são temáticas complexas que provocam diversas indagações tanto no universo profissional quanto no de pessoas que experienciam processos de adoecimento em seu cotidiano. Podemos afirmar, dessa forma, que se tratam de fenômenos que atravessam tantos os aspectos biomédicos quanto as sociabilidades. Ao dissertarmos sobre a saúde, temos que a Organização Mundial da Saúde (OMS), no ano de 1946, definiu este termo como "um completo estado de bem-estar físico, mental e social, e não apenas ausência de doença". Como extensamente argumentado na literatura, "um completo estado de bem-estar" pode ser inviável para a condição humana (FERREIRA et al., 2014). Esta inviabilidade do completo bem-estar vem ao encontro à literatura ao discorrer que a saúde está associada aos aspectos sociais, econômicos, políticos e culturais. Posteriormente, em 1998, a OMS propôs uma nova definição, apresentando o conceito de saúde como multideterminado e em uma perspectiva biopsicossocial, explicitando de modo mais direto que a religiosidade/espiritualidade seria um dos vértices dessa noção (WORLD HEALTH ORGANIZATION, 1998).

A ampliação desse conceito vem orientando diversas práticas em saúde e mesmo a revisão de protocolos de cuidado, como recentemente observado pela Sociedade Brasileira de Cardiologia (SBC), em 2019, que incluiu a necessidade de os profissionais da área realizarem a chamada anamnese espiritual, ou seja, uma investigação acerca da dimensão religiosa e espiritual do paciente, a fim de conhecer se ele possui crenças e filiações religiosas e também se ele recorre a essas referências tanto quando enfrenta processos de adoecimento como quando busca promover a saúde em seu cotidiano (PRÉCOMA et al., 2019). Esse olhar que integra as religiosidades e as espiritualidades ao contexto do adoecimento e da saúde, no entanto, não é uma ideia recente e atravessa, histórica e culturalmente, a formação das mais diversas sociedades, como podemos apreender ao explorarmos algumas religiões tradicionais, a exemplo das de matrizes africanas. Outro exemplo é o xamanismo, fortemente sustentado nas relações entre natureza e cura (LANGDON, 1996; PÉREZGIL, 2001).

Podemos considerar que os contextos que permeiam os processos de saúde-doença são subjetivos e resultantes de inúmeros aspectos como determinantes sociais, étnicos, psicológicos, comportamentais, entre outros, que podem estar relacionados à manifestação de doenças, comprometendo a qualidade de vida dos sujeitos (SANTOS et al., 2014). Este fato pode estar relacionado, ainda, às complexidades da atualidade, com novos hábitos e parâmetros comportamentais, que podem favorecer o acometimento patológico (CÂMARA et al., 2012). Desse modo, o olhar para os processos de saúde e doença deve ser múltiplo e integrativo.

Nesse cenário, alguns comportamentos determinantes podem beneficiar os cuidados com a saúde. Temos que o envolvimento em atividades de cunho religioso/espiritual maximiza pensamentos otimistas, constituindo-se como mecanismo de resiliência para impasses pessoais e questionamentos existenciais, proporcionando alívio e tranquilidade aos seus praticantes, minimizando sofrimentos diante do adoecimento (AMARAL et al., 2016). Nesse sentido, observamos um crescente interesse neste assunto, abordando o papel do enfrentamento religioso nas condições de saúde, identificando que comportamentos religiosos minimizam e previnem consequências emocionais, auxiliando na superação de adversidades, bem como na adoção de hábitos mais saudáveis, maior adesão e engajamento em tratamentos e promoção de saúde (PRÉCOMA et al., 2019). Em um movimento oposto, mas substancialmente menos expressivo, também encontramos estudos que destacam que a religiosidade e a espiritualidade também podem estar associadas a desfechos negativos, sobretudo quando atreladas ao fanatismo religioso, à recusa em dialogar com recomendações dos setores formais de saúde e à busca por explicações espirituais para o adoecimento (PARK; CHO, 2017). 
Para esse conjunto de estudos, ainda, apesar de a religiosidade e a espiritualidade poderem ser evocadas nos contextos de adoecimento, teriam pouca implicação em tratamentos e processos de cura (RUMBOLD, 2007).

Consideramos que as crenças religiosas estão presentes no cotidiano, o que fundamenta a intensa busca para tentar entender os possíveis benefícios destas sobre as queixas de saúde. Neste campo, o presente estudo debruça-se sobre o universo da umbanda, considerada uma religião eminentemente brasileira a qual as pessoas recorrem, muitas vezes, para se readaptarem e lidarem com adversidades e processos de adoecimento (ABDALA et al., 2015).

A alcunha de religião brasileira deve-se ao fato de mesclar, em seu panteão, elementos das tradições que compõem o povo brasileiro, resgatando marcadores indígenas, africanos e europeus, bem como aportes em religiões como o catolicismo, o espiritismo kardecista e o candomblé africano. Por propor a integração desses elementos, o modo como os processos de saúde-doença são interpretados na umbanda fazem referência a esses aspectos trabalhados por diferentes religiões e culturas, em uma perspectiva de diversidade e, ao mesmo tempo, de complexidade. Ainda que traga em si a marca de uma miscigenação, sugerindo uma bricolagem de elementos, a umbanda deve ser analisada de modo integrativo e como um conhecimento que possui uma unidade. Em que pesem as diferentes versões sobre a origem da umbanda, retomamos que uma das interpretações para o significado do termo umbanda é justamente a noção de saúde, uma espécie de magia, de arte de curar (OPIPARI, 2009).

Remontando a essa origem ligada à cura, podemos notar que, na umbanda, as demandas de saúde e de doença são frequentes nos atendimentos realizados à população, atribuindo-se às mesmas as motivações para a busca dessa religião, seus ritos e processos curativos (ANDRADE; MELLO; HOLANDA, 2015; SILVA; SCORSOLINICOMIN, 2020). As questões de saúde e de doença são valorizadas nesse cenário mediante a presença de entidades espirituais culturalmente conhecidas e associadas aos processos de cura de diversas doenças (MACEDO; BAIRRÃO, 2011; MONTERO, 1985).

Em que pesem as diferenças existentes na organização de cada terreiro, nessa religião os atendimentos ao público são realizados por meio de consultas mediúnicas em que os consulentes conversam com as entidades espirituais a partir de um médium em transe de possessão (SILVA; SCORSOLINI-COMIN, 2020). As entidades espirituais mais frequentes nos cultos umbandistas e incorporadas por esses médiuns são caboclos, pretos-velhos, baianos, marinheiros, boiadeiros e ciganos, considerados da linha da direita, bem como entidades da chamada linha de esquerda, composta por exus e pombagiras (MACEDO; BAIRRÃO, 2011). Na umbanda, a separação entre direita e esquerda não evoca a noção de bem e mal, mas de diferentes níveis de evolução espiritual e de proximidade com o humano. Nessa perspectiva, espíritos da linha de esquerda seriam considerados mais próximos dos humanos, motivo pelo qual seriam evocados para demandas relacionadas à abertura de caminhos. Já espíritos como caboclos e pretos-velhos seriam mais associados a trabalhos de cura.

Nesse universo religioso e simbólico houve interpretações equivocadas a respeito do contato com o mundo espiritual, com as condutas e orientações umbandistas que foram associadas às práticas de cunho negativo, denominadas de "feitiçarias", "macumba" e "baixo espiritismo", além do preconceito relacionado às classes sociais mais populares. No entanto, com o decorrer dos anos, deu-se o reconhecimento da umbanda e a sua relação moral, social e terapêutica dentro da sociedade, fato que corrobora estudos que retratam que os terreiros de umbanda auxiliam nos diversos problemas de saúde por meio de recursos utilizados pelas diversas matrizes culturais (ANDRADE; MELLO; HOLANDA, 2015; DELMONTE; FARIAS, 2017; GONÇALVES, 2011).

Apoiado na concepção das matrizes culturais e representativas da umbanda, os rituais 
religiosos (sessões mediúnicas) realizados no terreiro estimulam o processo intrínseco de cura de seus adeptos, permitindo modificações comportamentais, a compreensão das vivências religiosas e também espirituais, promovendo a reconstituição do corpo, fortalecendo-o fisicamente e mentalmente, minimizando os impactos causados pelo adoecimento (LANGDON, 2014; RABELO, 1994). Durante as sessões mediúnicas de cura, os participantes buscam auxílio nos aspectos que englobam os processos de saúde-doença, o que nos permite notar que a religiosidade vem ganhando espaço no tratamento de enfermidades, agindo de modo positivo sobre as questões de saúde dos indivíduos (ANDRADE; MELLO; HOLANDA, 2015; RABELO, 1994; SILVA; SCORSOLINICOMIN, 2020).

Diante disso, é importante entendermos o significado que o sujeito dá à doença, ao tratamento e ao seu itinerário. A procura pela umbanda para a assistência curativa independe da necessidade da conversão religiosa. Muitas pessoas recorrem à religião influenciadas pela crença na magia e pelo histórico cultural da eficiência da umbanda em livrar-se das forças sobrenaturais malignas, atribuindo a cura às entidades protetoras, a fim de solucionar situações conflituosas do cotidiano, como o adoecimento (REDKO, 2003). Fenômeno semelhante ocorre na busca de igrejas neopentecostais.

Embora a umbanda apresente um panteão explicativo acerca dos processos de saúde-doença e seja frequentemente buscada por pessoas com queixas de adoecimento, há a necessidade de compreender como os estudos científicos que possuem a umbanda como cenário exploram mais detidamente esses aspectos. Em que pese uma forte tradição da Antropologia e da Etnopsicologia em compreender esses processos, não apenas no Brasil, mas também no exterior, é mister não apenas revelar como esse panteão interpreta $o$ adoecimento, por exemplo, como desordem, mas também como pode contribuir na construção de práticas de saúde que serão ofertadas à população de adeptos que recorrem à umbanda com diferentes queixas (LUNDELL, 2016; MONTERO, 1985; RABELO, 1994). Assim, a meta é de não apenas sumarizar os elementos que tratam de saúdedoença na umbanda, mas como os mesmos podem disparar práticas na comunidade e, efetivamente, relacionar-se à promoção do cuidado, do acolhimento e da transmissão de saberes e referências acerca das noções de saúde e doença em equipamentos não oficiais de tratamento.

A partir desse panorama, o objetivo do presente estudo é apresentar uma revisão integrativa da literatura científica acerca dos processos saúde-doença no cenário umbandista, buscando evidenciar o perfil dos trabalhos publicados em fontes de pesquisa de impacto no contexto nacional e internacional, de modo a possibilitar um maior direcionamento dos estudos sobre o construto e discutir as tendências dessas publicações, bem como as perspectivas de produção na área. Esse levantamento mostrase oportuno, pois visa a cotejar a literatura mais recente nesse campo, a fim de contribuir com clássicos estudos sobre a relação da umbanda com o adoecimento (MONTERO, 1985), compreendendo de que modo esses atravessamentos (saúde, doença, cultura, religião) têm sido abordados contemporaneamente, bem como os novos conhecimentos produzidos. Ainda, tal estudo, dando visibilidade ao cenário da umbanda, pode contribuir para uma compreensão mais atual sobre o modo como essa religião tem atravessado as explicações, os tratamentos e os itinerários terapêuticos dos seus adeptos, em um contexto de cuidado que fortemente integra o pertencimento religioso (e o seu trânsito).

\section{Método}

\section{Tipo de estudo}

Trata-se de uma revisão integrativa da literatura científica nacional e internacional, que constitui uma ferramenta para a prática baseada em evidências. A pergunta norteadora elencada para esta revisão deu-se a partir da estratégia PICOT, 
que contempla os elementos Paciente, Intervenção, Comparação, Outcomes (desfecho) e Tempo, sendo uma estratégia alinhada aos pressupostos da prática baseada em evidências. Diante disso, para este estudo a pergunta norteadora recebeu a seguinte redação: "de que modo os processos de saúde e doença (I) são abordados (O) nos estudos que possuem a umbanda como cenário (P) no período de 2007 a 2018 (T)?”. Como a revisão não envolveu a comparação entre cenários, amostras, procedimentos ou técnicas, como encontrado nas revisões do campo das Ciências da Saúde, o elemento $\mathrm{C}$ não foi empregado na construção da pergunta. Há que se destacar que a estratégia PICOT pode ser customizada em função das características da revisão e também em termos do campo de estudos no qual ela é empregada, a exemplo da presente revisão, situada no domínio das Ciências Humanas e Sociais.

\section{Procedimentos de coleta e análise de dados}

Os procedimentos adotados, seguindo os protocolos da revisão integrativa, foram: (1) reconhecimento da temática a ser abordada e da questão norteadora do estudo; (2) definição dos critérios de inclusão/exclusão; (3) catalogação dos estudos; (4) análise dos estudos; (5) apreciação dos resultados e (6) síntese do conhecimento (MENDES; SILVEIRA; GALVÃO, 2008). O levantamento bibliográfico e o armazenamento das referências ocorreram de março a dezembro de 2018, por meio de dois juízes independentes, com familiaridade no desenvolvimento do tema abordado e na prática de revisão. As buscas ocorreram em uma rede de acesso público de uma universidade pública e em todas as bases de dados/bibliotecas foram utilizados os seguintes unitermos: religião, saúde, umbanda, doença e cura, bem como suas variantes em inglês e suas combinações.

Visando assegurar uma ampla abrangência desta revisão, foram consultadas as seguintes bases/ bibliotecas: Lilacs (Literatura Latino-Americana e do Caribe em Ciências da Saúde), SciELO
(Scientific Eletronic Library Online), PePSIC (Periódicos Eletrônicos de Psicologia), PsycINFO (American Psychological Association) e Medline (Medical Literature Analysis and Retrieval System Online). O período de abrangência da revisão foi de estudos publicados entre janeiro de 2007 e dezembro de 2018. Como critérios de inclusão, destacam-se: artigos indexados e disponíveis na íntegra; trabalhos publicados nos idiomas português, inglês ou espanhol e com temática apropriada aos objetivos da revisão, permitindo responder à pergunta norteadora.

Após o processo de rastreio e análise das evidências, o corpus final foi lido e interpretado a partir da construção de núcleos temáticos que englobam não apenas os resultados e tendências presentes nessa produção recuperada, como também contemplam, de modo integrado, a resposta à pergunta norteadora. Ainda, destacamos que a análise e a síntese desta revisão foram embasadas nas orientações do sistema PRISMA (Preferred Reporting Items for Systematic Reviews and Meta-Analysis), por meio de seus critérios e conforme a lista de verificação.

\section{Resultados}

Inicialmente, apreciamos de forma rigorosa e precisa os estudos encontrados $(N=11.636)$, objetivando elencar aqueles em que os títulos $(N=1.584)$ estivessem correlacionados aos temas propostos, como: religião, saúde, umbanda, doença e cura. Portanto, 10.052 artigos foram excluídos devido ao título estar fora do enfoque de interesse deste estudo. Posteriormente, realizamos uma leitura detalhada dos resumos recuperados, almejando selecionar apenas estudos significativos para este estudo e que respondessem à questão norteadora. Logo, foram excluídos 1.467 registros como artigos que não contemplavam o tema pesquisado ou que não permitiam responder à questão norteadora; artigos repetidos indexados nas diferentes bases de dados; livros, capítulos de livro, resenhas, revisões de literatura, resumos, anais de congressos, editoriais, cartas, notícias, 
dissertações e teses. Posteriormente à leitura dos resumos, os artigos recuperados foram analisados na íntegra, compondo o corpus analítico da revisão.

Ao final desse processo analítico, foram recuperados 22 estudos que responderam à questão norteadora. A partir do sistema de busca e seleção de evidências, representado na Figura 1, o maior número de artigos selecionados está concentrado na base de dados Medline, compondo 36,36\% $(\mathrm{n}=8)$. Os demais artigos foram recuperados nas bases Lilacs $(n=6)$, SciELO $(n=3)$, PePSIC $(n=2)$ e PsycINFO $(n=3)$.

Figura 1 - Fluxograma com os procedimentos de seleção dos artigos.

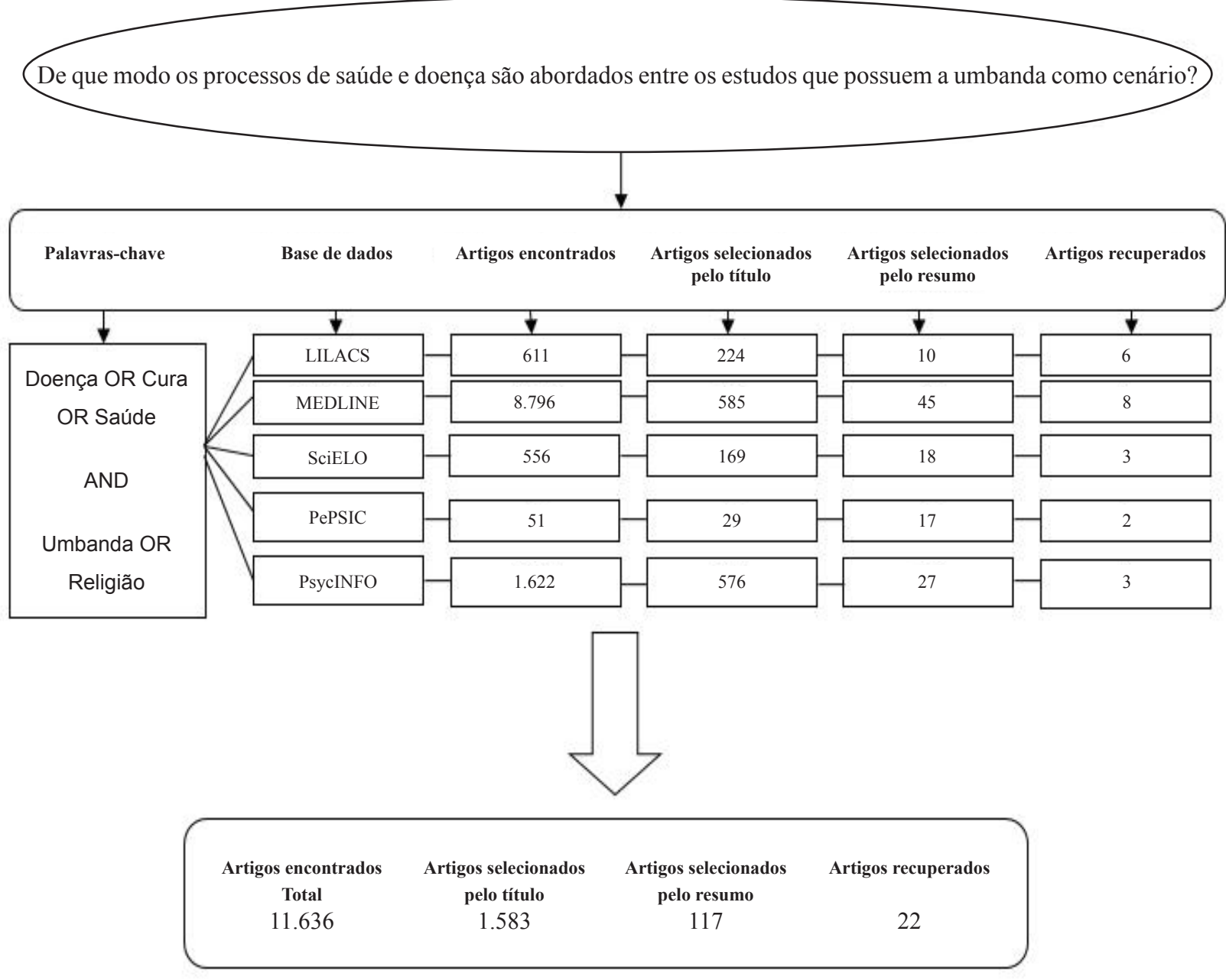

Fonte: Autores

Em termos do perfil da produção recuperada, 12 estudos foram publicados no Brasil, seis no estado de São Paulo e os demais no Rio Grande do Sul, Paraná e Rio de Janeiro. O restante da amostra $(\mathrm{N}=10)$ é composto de estudos em inglês, a maioria (60\%) publicados nos Estados Unidos, na Austrália e em Portugal. Nota-se uma média equiparada entre as publicações brasileiras e no exterior. A maioria dos estudos foi desenvolvida a partir de metodologias qualitativas. Destacase que o número de artigos publicados foi se intensificando ao longo do tempo, o que indica a necessidade de entendimento e maior interesse pela temática abordada nos últimos tempos, sendo que $63,63 \%$ dos artigos foram publicados entre 2013 e 2018 e 36,36\% publicados entre 2007 e 2012. A caracterização dos estudos em termos de tipos de pesquisa e desfechos encontra-se no Quadro 1. 
Quadro 1 - Caracterização dos artigos recuperados na revisão (N=22).

\begin{tabular}{|c|c|c|c|c|}
\hline $\mathbf{N}^{\circ}$ & Ano & $\begin{array}{l}\text { Tipo de } \\
\text { estudo }\end{array}$ & Autor(a) & Desfecho \\
\hline 1 & 2007 & QL* & Rumbold & $\begin{array}{l}\text { Considerando fatores biomédicos, a espiritualidade é um mecanismo de } \\
\text { enfrentamento desnecessário no tratamento de saúde. No entanto, alguns } \\
\text { profissionais consideram importante a associação do tratamento espiritual. }\end{array}$ \\
\hline 2 & 2007 & QL & Park & $\begin{array}{l}\text { As crises de saúde podem levar os indivíduos a questionar suas crenças, } \\
\text { porém as estratégias de enfrentamento religioso buscam conforto e } \\
\text { significado para a doença. }\end{array}$ \\
\hline 3 & 2008 & QL & Puttini & $\begin{array}{l}\text { Mediunidade como forma de renúncia e de caridade, havendo interação } \\
\text { entre o campo médico e religioso, perspectiva holística do processo saúde- } \\
\text { doença. }\end{array}$ \\
\hline 4 & 2008 & QL & Costa-Rosa & Pedidos de auxílio espiritual de natureza psíquica. \\
\hline 5 & 2009 & QL & Levin & $\begin{array}{l}\text { A doença é vista como um desequilíbrio espiritual. A fé e o otimismo } \\
\text { reduzem o sofrimento psíquico e aumentam a resiliência sendo um fator } \\
\text { produtivo da saúde. }\end{array}$ \\
\hline 6 & 2010 & QL & Alves et al. & $\begin{array}{l}\text { O enfrentamento religioso é significativo para os resultados de saúde física } \\
\text { e mental, para as circunstâncias da vida, especialmente os problemas de } \\
\text { saúde. }\end{array}$ \\
\hline 7 & 2011 & QL & Son \& Wilson & $\begin{array}{l}\text { Fatores religiosos influenciam sobre um conjunto diversificado de resultados } \\
\text { frente aos problemas de saúde. }\end{array}$ \\
\hline 8 & 2012 & $\mathrm{ET}^{* *}$ & Lages & $\begin{array}{l}\text { A religião leva a resultados positivos que tendem a uma melhor saúde. } \\
\text { O envolvimento religioso pode inibir comportamentos prejudiciais para a } \\
\text { saúde. }\end{array}$ \\
\hline 9 & 2013 & QT & Jordan et al. & Os poderes do sagrado auxiliam para a cura de uma doença. \\
\hline 10 & 2013 & $\mathrm{ET} / \mathrm{QL}$ & Lemos \& Bairrão & $\begin{array}{l}\text { Os processos interpessoais contribuem para a influência de } \mathrm{R} / \mathrm{S} \text { na saúde e } \\
\text { bem-estar, relacionado aos níveis elevados de apoio social. }\end{array}$ \\
\hline 11 & 2013 & QL & Mello \& Oliveira & Os processos de cura não envolvem apenas a remissão dos sintomas. \\
\hline 12 & 2014 & QL & Ferretti & Os problemas de saúde muitas vezes são a razão pela busca da ajuda religiosa. \\
\hline 13 & 2014 & QL & Scorsolini-Comin & Anteriormente acreditava-se na cura de doenças provocadas por feitiços. \\
\hline 14 & 2015 & QL & $\begin{array}{l}\text { Henriques, } \\
\text { Oliveira Filho } \\
\text { e Figueirêdo }\end{array}$ & $\begin{array}{l}\text { A relação entre espiritualidade e saúde é complexa e não é fácil articular, } \\
\text { porque nem todas as crenças e práticas religiosas têm uma influência } \\
\text { semelhante sobre os resultados de saúde e bem-estar. }\end{array}$ \\
\hline 15 & 2016 & QT & Hayward et al. & $\begin{array}{l}\text { A religião possibilita a cura de doenças do corpo e dos males do espírito, } \\
\text { sendo mais eficazes do que as práticas médicas e psicológicas. }\end{array}$ \\
\hline 16 & 2016 & QT & Tsai et al. & $\begin{array}{l}\text { As crenças religiosas podem melhorar as percepções internas de controle } \\
\text { que contribuem para os resultados de saúde e bem-estar. }\end{array}$ \\
\hline 17 & 2017 & QL & Scorsolini-Comin & $\begin{array}{l}\text { A atividade religiosa está relacionada à satisfação com a vida e maior crença } \\
\text { na cura. }\end{array}$ \\
\hline 18 & 2017 & $\mathrm{ET} / \mathrm{QL}$ & Scorsolini-Comin & $\begin{array}{l}\text { A religião influencia positivamente a saúde espiritual, emocional e mental, } \\
\text { gerenciando o processo de tratamento e incapacidade causada pelas doenças. }\end{array}$ \\
\hline 19 & 2017 & QL & $\begin{array}{l}\text { Marin \& } \\
\text { Scorsolini-Comin }\end{array}$ & $\begin{array}{l}\text { A espiritualidade reduz os períodos de internação e melhora os níveis de } \\
\text { resiliência diante do adoecimento. }\end{array}$ \\
\hline 20 & 2017 & QT & Hvidt et al. & Os elementos espirituais possuem um efeito terapêutico. \\
\hline 21 & 2018 & QT & Altun et al. & $\begin{array}{l}\text { A R/E constituem o sujeito que ao confrontar com problemas tendem a orar } \\
\text { mais e encontrar a fé em Deus. }\end{array}$ \\
\hline 22 & 2018 & QT & Weber \& Lins & $\begin{array}{l}\text { A fé religiosa e os rituais podem ajudar as pessoas a procurar novas formas } \\
\text { de tratamento, manter o tratamento e adotar novos comportamentos de } \\
\text { saúde. }\end{array}$ \\
\hline
\end{tabular}

Fonte: Autores

*QL: qualitativo; **ET: etnografia. 
Por meio da análise dos registros recuperados notamos que há um consenso entre estudos publicados em português e em inglês quanto à influência do contexto religioso como estratégia de enfrentamento e resiliência perante o adoecimento, sendo este contexto de suma importância para a recuperação do estado de saúde dos sujeitos. Identificamos que o cenário umbandista é visto como um espaço de acolhimento físico, mental e espiritual, marcado pela assistência à saúde e pela caridade, conceituada e compreendida como forma de cuidado espiritual, o que vem atraindo novos adeptos à religião. Este cenário também vem sendo considerado um ambiente de disseminação e troca de conhecimentos relacionados às orientações e educação em saúde, haja vista que um número significativo de adeptos recorre à religião almejando o alívio de desconfortos nas questões de saúde, e a partir desse momento atribuem mudanças positivas no seu estilo de vida (SILVA; SCORSOLINICOMIN, 2020).

Ressaltamos que os estudos se apresentaram de modo diversificado, contemplando diferentes amostras, dentre elas sujeitos adeptos ou frequentadores da umbanda, dirigentes e médiuns do terreiro e indivíduos que se encontravam em tratamentos formais de saúde. Apenas um estudo apresentou a visão de um relato da experiência profissional integrada à participação na umbanda, identificando os benefícios da crença religiosa umbandista diante de melhores níveis de resiliência e enfrentamento de quadros de enfermidade. Nesse sentido, este presente estudo de revisão oferece possibilidades para refletirmos sobre os aspectos que compõem a comunidade umbandista, suas crenças, costumes e valores que integram esta religião.

A posteriori, definimos a análise deste estudo a partir de três categorias construídas por meio da leitura dos artigos recuperados, bem como da utilização de referências destaque para o tema em questão. As categorias delimitadas a partir dos conteúdos presentes no corpus foram: (1) entendendo o adoecimento na umbanda; (2) a crença religiosa como estratégia de enfrentamento; (3) rituais de cura, práticas espirituais curativas e os processos de saúde-doença. Ressaltamos que esta categorização permitiu a reflexão crítica a respeito da dimensão dos processos saúde-doença na umbanda. A produção de resultados e da discussão acompanhará essas categorias temáticas, apresentadas a seguir.

\section{Discussão}

\section{Entendendo o adoecimento na umbanda}

Esta categoria retrata o entendimento sobre o adoecimento ao se falar dos processos de saúdedoença no contexto da umbanda. Nos estudos de Lages (2012) e Mello e Oliveira (2013), os autores destacam que a busca pelo entendimento e a interpretação sobre o adoecimento fazem com que os sujeitos recorram a outros espaços que contemplem as concepções sobre saúde-doença, como as instituições religiosas que abordam as vivências da doença, o sofrimento e a dor causados pela mesma e as práticas de cura como forma de tratamento.

Lages (2012) destaca que as instituições religiosas trabalham com um parecer amplo em relação às vivências dos seres humanos, considerando o ser único em sua esfera física, mental e espiritual, almejando o conforto e o alívio de situações árduas do cotidiano. A autora ressalta que o desequilíbrio nessas dimensões pode ser o causador de diversas enfermidades, sendo estas muitas vezes entendidas como uma expiação individual ou coletiva, como missão ou provação Divina. Essa noção de desequilíbrio vem ao encontro dos argumentos apresentados por Santos et al. (2014), que enfatizam que os processos de saúde-doença podem ser resultantes de inúmeros fatores físicos, psicológicos e comportamentais que intensificam o risco de adoecimento, comprometendo a qualidade de vida dos sujeitos.

$$
\text { Costa-Rosa (2008) também trabalha }
$$
nessa mesma vertente, considerando o sujeito holisticamente, evidenciando que a busca pelo entendimento pode surgir pela inquietação das queixas de saúde que não apresentam fundamentos orgânicos e diagnósticos prescritos. Esse fato 
proporciona sofrimento psíquico e, por vezes, leva os sujeitos a recorrerem a serviços de outra natureza para compreender os processos de saúdedoença, almejando atribuir significados e formas de tratamento e cura.

Segundo Hayward et al.(2016), compreender os motivos que levaram ao desequilíbrio da saúde ou ao adoecimento e ter uma crença religiosa são fatores que podem maximizar a sensação de bem-estar. Esse aspecto é reforçado diante da percepção desenvolvida ao longo do tempo de que o poder superior benevolente está no controle dos acontecimentos e tudo ocorre conforme merecimento pessoal.

Os processos de saúde-doença estariam subordinados à "lei" espírita de causa e efeito, que enfatiza que os sujeitos têm como merecimento aquilo que fizeram ao próximo. Essa "lei" também se mostra presente nos estudos sobre a umbanda, haja vista o diálogo que ela estabelece com as chamadas religiões espiritualistas, sobretudo com o kardecismo que também se encontra na base de seus pressupostos. Diante do adoecimento as pessoas recorrem aos cultos umbandistas almejando alívio para o corpo físico e para aflições da alma (FERRETTI, 2014; MELLO; OLIVEIRA, 2013).

No entanto, Park (2007) destaca que os momentos de adoecimento podem levar os sujeitos a um questionamento de suas crenças e sua religiosidade, resultando muitas vezes em sentimentos negativos, que são trabalhados pelo uso de estratégias de enfrentamento religioso, apoio espiritual ou intensificação da busca religiosa, mas que não necessariamente estão relacionados a uma boa condição de saúde. Sentido semelhante emergiu em outros estudos (HENRIQUES; OLIVEIRA FILHO; FIGUEIRÊDO, 2015; HVIDT et al., 2017; MARIN; SCORSOLINI-COMIN, 2017).

\section{A crença religiosa como estratégia de enfrentamento}

Os artigos recuperados nesta categoria mostram que o reconhecimento e a confiança em algo superior fazem parte de um construto do envolvimento religioso no qual identifica-se a religião como uma potencial fonte de ajuda e cura, sendo a maior parte dos pedidos de ajuda de natureza psíquica. Esses estudos compreendem a religião como estratégia de suporte e enfrentamento para condições de adoecimento, aumentando-se o nível de resiliência perante as adversidades (COSTAROSA, 2008; FERRETTI, 2014; HVIDT et al., 2017; MARIN; SCORSOLINI-COMIN, 2017).

Nos trabalhos apresentados entre 2011 e 2017, nota-se o interesse por compreender a relação entre o tratamento biomédico associado ao tratamento espiritual, bem como a abordagem da saúde de modo holístico, considerando o ser em suas dimensões física, mental e espiritual, enfatizando a relevância das crenças religiosas frente aos processos de adoecimento e acreditando principalmente na cura de doenças que foram provocadas por meio de "feitiços". Destacamos que durante a realização das atividades religiosas as entidades em transe espiritual voltam-se para as práticas de cura, limpeza espiritual e aconselhamento e que na maioria das situações a busca pela ajuda religiosa se dá a partir dos problemas de saúde, âmbito em que a cura não envolve apenas a remissão dos sintomas (FERREIRA et al., 2014; FERRETTI, 2014; LAGES, 2012; LEMOS; BAIRRÃO, 2013; MELLO; OLIVEIRA, 2013).

Nesse sentido, os estudos contemplam a magnitude da assistência proporcionada pela religiosidade, abordando que as crenças religiosas constituem o sujeito e possuem um efeito terapêutico diante do adoecimento. No entanto, vale ressaltarmos que esse efeito terapêutico está associado à magnitude das crenças religiosas e espirituais, bem como da influência destas na vida dos sujeitos. Identificamos a proporcionalidade entre a magnitude do significado da religião no cotidiano dos sujeitos e os melhores níveis de resiliência diante do sofrimento que, muitas vezes, é amenizado por meio de auxílio/orientação espiritual para problemáticas de diferentes ordens (FERRETTI, 2014; HVIDT et al., 2017; MARIN; SCORSOLINI-COMIN, 2017; SCORSOLINICOMIN, 2014, 2015, 2017). 
As crenças e os valores religiosos demonstram o respeito da comunidade a uma cultura específica, como a umbanda, religião repleta de significados e costumes que por vezes pode ser negligenciada por saberes científicos dentro de um sistema formal de atendimento à saúde. Segundo a literatura recuperada, os elementos espirituais presentes no campo das religiões de matriz africana possuem um efeito terapêutico, auxiliando nos processos de cura. São elementos substanciais da vitalidade do ser humano, operando como motivador dos tratamentos em saúde, minimizando extensos períodos de internação e prosperando melhores condições de resiliência e enfrentamento mediante o adoecimento (LAGES, 2012; SCORSOLINICOMIN, 2015，2017; SCORSOLINI-COMIN; BAIRRÃO; SANTOS, 2017). Essa relação de motivação, resiliência e enfrentamento de adversidades com o auxílio das questões religiosas vai ao encontro do que foi enfatizado no estudo de Amaral et al. (2016), que destaca que as atividades de cunho religioso e/ou espiritual maximizam pensamentos otimistas, minimizando sofrimentos diante do adoecimento e auxiliando na superação de adversidades.

Mello e Oliveira (2013) destacam a relação estabelecida entre as crenças espirituais associadas às práticas de cura, enfatizando que somente $\mathrm{o}$ modelo biomédico torna-se insuficiente para lidar com as problemáticas de saúde e, diante deste fato, boa parcela da população recorre às influências religiosas e culturais na tentativa de aliviar o sofrimento. Nesse sentido, subentendemos que as ações de cura no universo religioso buscam trabalhar com a atenção integral ao paciente, considerando seu contexto biológico, social, cultural e espiritual, entendendo o tratamento umbandista como complementar às práticas médicas oficiais, mesmo em locais com acesso ao sistema de saúde tradicional.

Compreendemos que esse envolvimento religioso está associado a uma melhora na condição de saúde proporcionando maior longevidade e melhor qualidade de vida (AGLI; BAILLY; FERRAND, 2014). Destacamos que essas mudanças benéficas em relação à saúde podem se dar devido a níveis mais elevados de autoestima e apoio social e a um sentimento de pertencimento nas comunidades religiosas (JORDAN et al., 2013).

Rituais de cura, práticas espirituais curativas e os processos de saúde-doença

Esta categoria engloba o desenvolvimento dos rituais e práticas curativas, retratando sobre a influência destes nos processos de saúde-doença. De modo geral, identificamos em diversos estudos que a religião atua na cura de doenças do corpo físico e dos malefícios espirituais. A procura pela espiritualidade e a religiosidade possivelmente se dá em decorrência do reconhecimento e da crença em algo superior, da busca pelo entendimento e aceitação do adoecimento ou da necessidade do suporte da dimensão espiritual nos aspectos emocionais e no apoio nas práticas de saúde (HVIDT et al., 2017; SCORSOLINI-COMIN, 2014).

A dimensão espiritual é de extrema importância para as vivências humanas, sendo considerada e inserida no conceito atualizado e multidimensional de saúde da Organização Mundial de Saúde (OMS), como forma holística de compreender os indivíduos. Na umbanda, religião que pode ser apreendida como de caráter assistencial e solidário, compreendemos que o equilíbrio entre o corpo físico e os processos mentais é caracterizado pela influência de forças externas que regem o adoecimento e que podem ser afastadas por intermédio dos rituais umbandistas, do uso da medicina popular para os processos de cura e do otimismo perante as situações (LAGES, 2012; SCORSOLINI-COMIN, 2015).

Os rituais umbandistas ocupavam uma posição hierarquicamente inferior às demais religiões mediúnicas brasileiras, sobretudo no início do século XX, sendo tipificados por fenômenos mágicos que ameaçavam a ordem social. Alguns apontamentos podem ser realizados no sentido de compreender essa marginalidade da umbanda. $\mathrm{O}$ primeiro deles se refere ao fato de a umbanda ser uma religião de matriz africana, o que, ao longo 
do tempo, tem sido atravessado por preconceito, racismo e intolerância em nosso contexto. Outro apontamento que pode ser aventado refere-se ao domínio dos rituais praticados na umbanda. As práticas e tratamentos de cura na umbanda apontam que o adoecimento físico ou psíquico pode estar ligado à "feitiçaria", sendo esta provocada ou encomendada por pessoas que tem por objetivo direcionar malefícios ao próximo (ALTUN et al., 2018). Essa chamada "feitiçaria" seria aqui recoberta por um sentido depreciativo e carregado de estereotipias, reforçando o argumento acerca das assimetrias entre a umbanda e outras religiões mediúnicas, como o espiritismo kardecista. Tais elementos, embora datados, continuam a compor o cenário religioso brasileiro, desconstruindo a noção bastante difundida no senso comum de um país sem preconceitos ou tolerante com as diferentes crenças.

No entanto, por meio dos poderes do sagrado, a umbanda almeja combater essas práticas de malefícios adotando novos pensamentos e comportamentos relacionados à saúde. Durante os rituais de cura, ocorre a saudação às entidades e a execução de cânticos acompanhados pela assistência com objetivo de entrar em contato com a atmosfera espiritual e com entidades conhecidas como "bons curadores" que desempenham o papel de alicerce das práticas em saúde (ALTUN et al., 2018; FERRETTI, 2014; JORDAN et al., 2013). No estudo de Macedo e Bairrão (2011) também foi possível identificar a assistência das questões de saúde no cenário umbandista com o auxílio de entidades espirituais culturalmente conhecidas e associadas aos processos de cura de diversas doenças, como caboclos e pretos-velhos.

No estudo de Lemos e Bairrão (2013) encontramos uma outra vertente que faz uma associação entre a cura, o adoecimento e a mediunidade. Os autores trabalham com a concepção de que desenvolvendo a mediunidade eventualmente pode-se minimizar as problemáticas do adoecimento; a mediunidade não desenvolvida pode justificar inúmeras enfermidades influenciadas por obsessores e experiências de adoecimento como forma de redenção espiritual, que podem ser minimizadas com a prática mediúnica e a virtude da caridade.

Diante de inúmeras dificuldades, notamos que as práticas de cura operam como referência na umbanda, podendo atuar até mesmo como um atrativo à conversão religiosa, mas que muitos consulentes procuram esta religião para receberem orientações espirituais para os enfrentamentos cotidianos e para passes de descarrego (limpeza de energias negativas) com uso de ervas, chás, banhos e defumação e não necessariamente a possibilidade de cura, como visto no estudo de Scorsolini-Comin (2014).

Destacamos que o enfrentamento religioso e a manutenção ou o enfraquecimento do axé força vital, que é transmitida aos sujeitos durante os rituais de cura são significativos para uma boa condição de saúde (MELLO; OLIVEIRA, 2013). Os benefícios do poder de cura de fé proporcionam às práticas espirituais curativas um olhar diferenciado, focado na promoção do bem-estar estimulado pela esperança, confiança e otimismo (ALVES et al., 2010; HENRIQUES; OLIVEIRA FILHO; FIGUEIRÊDO, 2015). Nesse sentido, podemos inferir que os rituais e práticas de cura são conhecidos por seus resultados positivos e pelos benefícios à saúde daqueles que recorrem a este tipo de tratamento.

A partir do corpo de literatura analisado e recuperado na presente revisão, a religiosidade e a espiritualidade compõem pontos de ancoragem, ancestralidade e resistência na assistência e na cura dentro dos processos de saúde-doença, funcionando como elementos que devem ser conhecidos pelos profissionais de saúde para uma abordagem mais próxima dos pacientes e de seus universos de referência. A umbanda pode e deve ser apreendida como um elemento que também costura esses processos de saúde-doença não no sentido de oferecer uma resposta ao paciente que seja considerada alternativa, mas justamente integrada a modelos oficiais e formais de saúde e cuidado. Essa integração parece ser um desafio presente a partir da análise da produção em retrato. 


\section{Considerações Finais}

O objetivo deste estudo foi apresentar uma revisão integrativa da literatura científica acerca dos processos saúde-doença no cenário umbandista. A complexidade deste tema fica evidente quando nos deparamos com estudos que trazem que as práticas religiosas e espirituais como importantes elementos culturais, sociais e históricos desde os tempos mais remotos. Na contemporaneidade, busca-se compreender como estas são empregadas como forma de apoio e de fortalecimento perante as inúmeras adversidades do cotidiano.

Evidenciamos que no cenário umbandista os processos de saúde-doença são identificados como forma de remissão dos resquícios de vidas passadas, como resgate de comportamentos remanescentes vivenciados em outras experiências, ou como influências de energias externas do universo espiritual, ou ainda como merecimento pessoal em respeito ao seu comportamento com o próximo, com atitudes benéficas exaltadas diante de um poder superior.

No entanto, ainda existem lacunas a serem compreendidas e alguns questionamentos abrem possibilidades de interlocução a serem investigadas por estudos futuros: quais as especificidades culturais dos processos saúde-doença na umbanda? Podemos uniformizar esses processos, como se a umbanda tivesse uma abordagem única e colocada em prática em todos os seus espaços institucionais? Qual a visão popular a respeito das práticas assistencialistas com as diferentes linhas espirituais de atendimento na umbanda? Quais espaços as práticas de cura têm ocupado em investigações específicas na temática da umbanda? Estas lacunas somente o conhecimento científico poderá minorar diante das limitações que reforçam as barreiras de pesquisa e de vivência na umbanda, como o préjulgamento estabelecido quanto aos tratamentos com entidades espirituais.

Quanto às limitações do estudo, destacamos o universo ainda restrito dessas produções, com muitos estudos provenientes de poucos núcleos de pesquisa. Consideramos que, embora os processos de adoecimento estejam sendo cada vez mais estudados na sua interface com as religiosidades e as espiritualidades, o campo das religiões de matriz africana no qual se enquadra a umbanda ainda é considerado marginal no meio científico, sobretudo quando se relaciona às práticas de cuidado. Outras estratégias de buscas futuras podem envolver trabalhos divulgados em teses, dissertações, livros e demais materiais bibliográficos, ampliando as evidências disponíveis, ainda que este método não seja recomendado pelos protocolos de revisão sistematizada em vigência.

Por ora, destacamos que a revisão integrativa permitiu sistematizar as produções veiculadas na contemporaneidade, dando visibilidade para o conhecimento produzido e, ao mesmo tempo, apontando as áreas lacunares, a fim de contribuir com o delineamento de novas investigações e novos saberes, na medida da urgência da demanda científica. Enfatizamos que estes estudos devem estar pautados em critérios científicos rígidos, a fim de que possam agregar conhecimentos aos estudos já produzidos, cientificizando um campo por séculos tido como místico e distanciado.

\section{Referências}

ABDALA, G. A.; KIMURA, M.; DUARTE, Y. A. D. O.; LEBRÃO, M. L.; SANTOS, B. D. Religiosidade e qualidade de vida relacionada à saúde do idoso. Revista de Saúde Pública, São Paulo, v. 49, n. 55, p. 1-9, 2015.

AGLI, O.; BAILLY, N.; FERRAND, C. Spirituality and religion in older adults with dementia: a systematic review. International Psychogeriatrics, New York, v. 27, n. 5, p. 715-725, 2014.

ALTUN, Ö. Ş.; KARAKAS, S. A.; OLÇUN, Z.; POLAT, H. An investigation of the relationship between schizophrenic patients' strength of religious faith and adherence to treatment. Archives of Psychiatric Nursing, Philadelphia, v. 32, n. 1, p. 62-65, 2018.

ALVES, R. R. D. N.;ALVES, H. D. N.; BARBOZA, R. R. D.; SOUTO, W. D. M. S. The influence of religiosity on health. Ciência \& Saúde Coletiva, Rio de Janeiro, v. 15, n. 4, p. 2105-2111, 2010. 
AMARAL, J. B. do, MENEZES, M. D. R. de; SILVA, V. A. da; OLIVEIRA, C. M. S. de. A religiosidade e a espiritualidade como referências para o enfrentamento da violência doméstica contra idosos. Revista Enfermagem UERJ, Rio de Janeiro, v. 24, n. 2, p. e7126, 2016.

ANDRADE, J. T.; MELLO, M. L.; HOLANDA, V. M. S. (org.). Saúde e cultura: diversidades terapêuticas e religiosas. Fortaleza: EdUECE, 2015.

CÂMARA, A. M. C. S.; MELO, V. L. C.; GOMES, M. G. P.; PENA, B. C.; SILVA, A. P. D.; OLIVEIRA, K. M. D.; VICTORINO, L. R. Percepção do processo saúde-doença: significados e valores da Educação em Saúde. Revista Brasileira de Educação Médica, Rio de Janeiro, v. 36, n. 1, p. 40-50, 2012.

COSTA-ROSA, A. Práticas de cura místicoreligiosas, psicoterapia e subjetividade contemporânea. Psicologia USP, São Paulo, v. 19, n. 4, p. 561-590, 2008.

DELMONTE, R.; FARIAS, M. A mente brasileira em estado de possessão: contribuição de um estudo de caso para a psicologia da religião e saúde mental no Brasil. Revista Pistis Práxis: Teologia e Pastoral, Curitiba, v. 9, n. 1, p. 243-256, 2017.

FERREIRA, D. C.; SOUZA, I. D.; ASSIS, C. R. S.; RIBEIRO, M. S. A experiência do adoecer: uma discussão sobre saúde, doença e valores. Revista Brasileira de Educação Médica, Rio de Janeiro, v. 38, n. 2, p. 283-288, 2014.

FERRETTI, M. Brinquedo de cura em terreiro de Mina. Revista do Instituto de Estudos Brasileiros, São Paulo, v. 59, n. 1, p. 57-78, 2014.

GONÇALVES, D. J. A teoria da antropologia da saúde e sua contribuição para a saúde relacional nas organizações. Revista Ethnic, [S. l], v. 15, n. 8, p. 2-16, 2011.

HAYWARD, R. D.; KRAUSE, N.; IRONSON, G.; PARGAMENT, K. I. Externalizing religious health beliefs and health and well-being outcomes. Journal of Behavioral Medicine, New York, v. 39, n. 5, p. 887-895, 2016.
HENRIQUES, H. I. B.; OLIVEIRA FILHO, P.; FIGUEIRÊDO, A. A. F. Discursos de usuários de CAPS sobre práticas terapêuticas e religiosas. Psicologia e Sociedade, Belo Horizonte, v. 27, n. 2, p. 302-311, 2015.

HVIDT,N.C.; HVIDTJØRN, D.; CHRISTENSEN, K.; NIELSEN, J. B.; SØNDERGAARD, J. Faith moves mountains - mountains move faith: two opposite epidemiological forces in research on religion and health. Journal of Religion and Health, New York, v. 56, n. 1, p. 294-304, 2017.

JORDAN, K. D.; MASTERS, K. S.; HOOKER, S. A.; RUIZ, J. M.; SMITH, T. W. An interpersonal approach to religiousness and spirituality: implications for health and well-being. Journal of Personality, Durham, v. 82, n. 5, p. 418-431, 2013.

LAGES, S. R. C. Saúde da população negra: A religiosidade afro-brasileira e a saúde pública. Psicologia Argumento, Curitiba, v. 30, n. 69, p. 401-410, 2012.

LANGDON, E. J. Os diálogos da antropologia com a saúde: contribuições para as políticas públicas. Ciência \& Saúde Coletiva, Rio de Janeiro, v. 19, n. 4, p. 1019-1029, 2014.

LANGDON, E. J. Xamanismo: velhas e novas perspectivas. In: LANGDON, E. J. (org.). Xamanismo no Brasil: novas perspectivas. Florianópolis: Editora da Universidade Federal de Santa Catarina, 1996, p. 9-37.

LEMOS, D. T. A.; BAIRRÃO, J. F. M. H. Doença e morte na umbanda branca: a Legião Branca Mestre Jesus. Estudos e Pesquisas em Psicologia, Rio de Janeiro, v. 13, n. 2, p. 677-703, 2013.

LUNDELL, E. A. Exú's work: The Agency of Ritual Objects in Southeast Brazilian Umbanda. Journal of Ethnology and Folkloristics, Tartu, v. 10, n. 1, p. 43-69, 2016.

MACEDO, A. C.; BAIRRÃO, J. F. M. H. Estrela que vem do Norte: os baianos na umbanda de São Paulo. Paidéia, Ribeirão Preto, v. 21, n. 49, p. $207-$ 216, 2011. 
MARIN, R. C.; SCORSOLINI-COMIN, F. Desfazendo o "mau-olhado": magia, saúde e desenvolvimento no ofício das benzedeiras. Psicologia: Ciência e Profissão, Brasília, v. 37, n. 2, p. 446-460, 2017.

MELLO, M. L.; OLIVEIRA, S. S. Saúde, religião e cultura: um diálogo a partir das práticas afrobrasileiras. Saúde e Sociedade, São Paulo, v. 22, n. 4, p. 1024-1035, 2013.

MENDES, K. D. S.; SILVEIRA, R. C. C. P.; GALVÃO, C. M. Revisão integrativa: método de pesquisa para a incorporação de evidências na saúde e na enfermagem. Texto \& Contexto Enfermagem, Florianópolis, v. 17, n. 4, p. 758-764, 2008.

MONTERO, P. Da doença à desordem: a magia na umbanda. Rio de Janeiro: Graal, 1985.

OPIPARI, C. O candomblé: imagens em movimento: São Paulo-Brasil. Tradução de A. L. Costa. São Paulo: Edusp, 2009.

PARK, C. L. Religiousness/spirituality and health: a meaning systems perspective. Journal of Behavioral Medicine, New York, v. 30, n. 4, p. 319-328, 2007.

PARK, C. L.; CHO, D. Spiritual well-being and spiritual distress predict adjustment in adolescent and young adult cancer survivors. PsychoOncology, Hoboken, v. 26, n. 9, p. 1293-1300, 2017.

PÉREZ-GIL, L. O sistema médico Yawanáwa e seus especialistas: cura, poder e iniciação xamânica. Cadernos de Saúde Pública, Rio de Janeiro, RJ, v. 17, n. 2, p. 333-344, 2001.

PRÉCOMA, D. B.; OLIVEIRA, G. M. M.; SIMÃO, A. F.; DUTRA, O. P.; COELHO, O. R.; IZAR, M. C. O. Atualização da diretriz de prevenção cardiovascular da Sociedade Brasileira de Cardiologia - 2019. Arquivos Brasileiros de Cardiologia, São Paulo, 2019. Ahead print.

RABELO, M. C. M. Religião, ritual e cura. In: ALVES, P. C.; MINAYO, M. C. S. (org.). Saúde e doença: um olhar antropológico. Rio de Janeiro: Fiocruz, 1994. p. 47-56.

REDKO, C. Religious construction of a first episode of psychosis in urban Brazil. Transcultural Psychiatry, London, v. 40, n. 4, p. 507-530, 2003.
RUMBOLD, B. D. A review of spiritual assessement in the health care practice. Medical Journal of Australia, Sydney, Australia, v. 186, n. 10, p. 60-62, 2007.

SANTOS, D. S.; ALBUQUERQUE, T. E. de; BRÊDA, M. Z.; MISHIMA, S. M. Processo saúde/ doença e estratégia de saúde da família: o olhar do usuário. Revista Latino-Americana de Enfermagem, Ribeirão Preto, v. 22, n. 6, p. 918-925, 2014.

SCORSOLINI-COMIN, F. Atenção psicológica e umbanda: experiência de cuidado e acolhimento em saúde mental. Estudos e Pesquisas em Psicologia, Rio de Janeiro, v. 14, n. 3, p. 773-794, 2014.

SCORSOLINI-COMIN，F. Espiritualidade e brasilidade na clínica etnopsicológica. Psicologia Clínica, Rio de Janeiro, v. 29, n. 2, p. 319-338, 2017.

SCORSOLINI-COMIN, F. Um toco e um divã: reflexões sobre a espiritualidade na clínica etnopsicológica. Contextos Clínicos, São Leopoldo, v. 8, n. 2, p. 114-127, 2015.

SCORSOLINI-COMIN, F.; BAIRRÃO, J. F. M. H.; SANTOS, M. A. (2017). Com a licença de Oxalá: a ética na pesquisa etnopsicológica em comunidades religiosas. Revista da SPAGESP, Ribeirão Preto, v. 18, n, 2, p. 86-99, 2017.

SILVA, L. M. F.; SCORSOLINI-COMIN, F. Na sala de espera do terreiro: uma investigação com adeptos da umbanda com queixas de adoecimento. Saúde e Sociedade, São Paulo, v. 29, n. 1, p. e190378, 2020.

WORLD HEALTH ORGANIZATION - WHO. Division of Mental Health and Prevention of Substance Abuse. WHOQOL and spirituality, religiousness and personal beliefs (SRPB). Genève: WHO, 1998. 